\title{
SINGLE-CHANNEL CURRENTS ACTIVATED BY CURARE IN CULTURED EMBRYONIC RAT MUSCLE ${ }^{1}$
}

\author{
CATHERINE E. MORRIS, ${ }^{2}$ BRENDAN S. WONG, ${ }^{3}$ MEYER B. JACKSON, ${ }^{4}$ AND HAROLD LECAR ${ }^{5}$ \\ Laboratory of Biophysics, National Institute of Neurological and Communicative Disorders and Strake, National Institutes of \\ Health, Bethesda, Maryland 20205
}

Received April 25, 1983; Revised July 14, 1983; Accepted July 15, 1983

\begin{abstract}
Single cholinergic receptor channel currents activated by curare were recorded in tissue-cultured embryonic rat muscle, directly confirming curare's action as a weak cholinergic agonist. In embryonic muscle, curare, in addition to its classical action as a competitive cholinergic antagonist, produces small sustained depolarizations which can be blocked by $\alpha$-bungarotoxin. The single-channel events are of short duration but otherwise exhibit the major features observed with other cholinergic agonists. The single-channel events are blocked by $\alpha$-bungarotoxin. Two values of unit conductance, $30.4 \pm 3.5 \mathrm{pS}$ and $47 \pm 6 \mathrm{pS}$, were measured in cells from different cultures. Histograms of openstate duration are well fit by a distribution which is a sum of two exponentials, with time constants of $0.33 \pm 0.08 \mathrm{msec}$ for the fast component and $1.84 \pm 0.43 \mathrm{msec}$ for the slow component.
\end{abstract}

The action of $d$-tubocurarine (curare) on the acetylcholine receptor $(\mathrm{AChR})$ was for many years considered to be one of the classical examples of competitive antagonism. Recent evidence suggests, however, that curare is not as incisive a pharmacological tool as had been thought. On Aplysia neurons, for example, the action of curare involves blockade of open ion channels rather than competition for the AChR (Ascher et al., 1978). In embryonic and neonatal rat muscle, curare not only diminishes the depolarizing effect of acetylcholine, but also produces, on its own, an $\alpha$-bungarotoxin-sensitive depolarization (Ziskind and Dennis, 1978).

In this paper, we demonstrate that the phenomenon of curare-induced depolarization occurs in tissue-cultured embryonic muscle exactly as it does in excised tissue, and that this depolarization is caused by the curare-activated openings of AChR ionic channels. The single-channel current jumps induced by curare are shown to have many features in common with channel

\footnotetext{
${ }^{1}$ C. E. M.'s research was supported in part by a grant from the Scottish Rite Foundation for Schizophrenia Research. We wish to thank Dr. S. Misler for his helpful comments on the manuscript and Dr. C. N. Christian for his aid in the early stages of the work.

${ }^{2}$ Present address: Department of Biology, University of Ottawa, Ottawa, Ontario, Canada K1N 6 N5.

${ }^{3}$ Present address: Department of Physiology, Baylor College of Dentistry, Dallas, TX 75246.

${ }^{4}$ Present address: Department of Biology, University of California, Los Angeles, Los Angeles, CA 90024.

${ }^{5}$ To whom correspondence should be addressed, at Building 36 , Room 2A29, National Institutes of Health, Bethesda, MD 20205.
}

activation by other agonists. First reports of curareinduced single-channel jumps have been given elsewhere (Jackson et al., 1982a; Morris et al., 1982; Trautmann, 1982). The present paper describes the stochastic properties of the current jumps in some detail, addressing the following questions: How do the conductances and open times of curare-induced current jumps compare with the corresponding properties obtained with other agonists? Do the kinetics of channel activation point to a mechanism for simultaneous activation and competitive antagonism of AChRs? Consideration of these questions suggests that, in embryonic muscle, curare is a drug which both activates and antagonizes the AChR, and thus can be considered to be a partial agonist.

\section{Materials and Methods}

Dissociated embryonic rat muscle was grown for 6 to 8 days in culture according to the methods of Nelson et al. (1976). The recording medium was HEPES-buffered Earle's basic salts solution with tetrodotoxin added to prevent spontaneous contraction. $d$-Tubocurarine chloride (curare) was obtained from Sigma Chemical Co. (St. Louis, MO) and diluted (from a $1 \mathrm{~mm}$ frozen stock solution) into Earle's solution just prior to use. Experiments were carried out at room temperature $\left(22^{\circ} \mathrm{C}\right)$.

To test the voltage response of cultured embryonic rat muscle to curare, $10 \mu \mathrm{M}$ curare was pressure ejected from a broken micropipette (10- $\mu \mathrm{m}$ opening) placed about 20 $\mu \mathrm{m}$ from the cell. The resting potential, determined immediately after impalement with two potassium acetate electrodes, was approximately $-55 \mathrm{mV}$. One elec- 
trode was used to measure the membrane potential, the other to pass current to displace the membrane potential, if necessary, before drug application. To provide a standard for comparison of the effects of curare, $0.1 \mu \mathrm{M}$ suberyldicholine, a powerful cholinergic agonist, was applied to the preparation.

Single-channel recordings of curare-induced currents were made using the techniques which have been described in detail elsewhere (Neher et al., 1978; Hamill et al., 1981). The patch electrode is a micropipette with a fire-polished tip with $0.5 \mu \mathrm{m}$ internal diameter filled with physiological saline and containing a low concentration of agonist. It is pressed against the cell surface, and gentle suction is applied to electrically isolate a small patch of membrane with a gigohm seal. This allows a low-noise current-measuring circuit to detect the opening and closing of individual channels within the patch.

All recordings were made on cell-attached membrane patches (Hamill et al., 1981), so that control of the transmembrane voltage across the patch required monitoring the intracellular potential. Because of the gigohm seal between micropipette and membrane, the transmembrane voltage at the patch could be controlled by measuring the intracellular voltage in the conventional manner, then raising or lowering the holding potential of the positive input of the current-measuring amplifier to achieve the desired transmembrane potential (Horn and Patlak, 1980; Sigworth and Neher, 1980). After filtering at $2 \mathrm{kHz}$ (3-dB down point), data were recorded on a digital oscilloscope/tape recorder at a sampling rate of $2 \times 10^{4} \mathrm{sec}^{-1}$. The rise time of the system, measured from the response to an input triangular wave, varied between 200 and $300 \mu$ sec. The rms noise level in a typical gigohm seal experiment, such as that of Figure 2, is between 0.2 and $0.3 \mathrm{pA}$.

Since the efficiency of detection of single-channel events falls off rapidly for events shorter than $500 \mu \mathrm{sec}$, open-state duration histograms were cut off at $500 \mu \mathrm{sec}$, as shown in the inset to Figure 5. The mean open time of the shorter curare openings ( $\sim 300 \mu \mathrm{sec})$ could be fit with a standard error of $3 \%$, so that bandwidth limitation did not pose a problem in characterizing the short openings. However, the short closings in the $100-\mu$ sec range which have been reported for AChR channels (Colquhoun and Sakmann, 1981) would not be resolved.

\section{Results}

Because the original observation that curare depolarizes embryonic muscle was made on freshly dissected fibers, we began by testing for depolarization on cultured embryonic cells. These tests were needed because no unexpected effect of curare had been reported in previous electrophysiological studies of cultured rat and mouse muscle cells (Fambrough and Rash, 1971; Nelson et al., 1976).

Figure 1 illustrates the effects of curare on cultured embryonic rat muscle. Curare produces a depolarization (Fig. 1b) which, by comparison to the suberyldicholineinduced depolarization (Fig. 1a), is decidedly weak. The depolarizing action of curare is blocked by pretreatment with $0.05 \mu \mathrm{M} \alpha$-bungarotoxin (Fig. 1c), a specific and essentially irreversible blocker of the AChR. Figure $1 d$ shows that, regardless of the starting potential, $10 \mu \mathrm{M}$ curare does not depolarize cells beyond about $-50 \mathrm{mV}$. This value does not, however, represent a reversal potential for the curare-induced response, since application of curare to cells depolarized beyond $-50 \mathrm{mV}$ by injected current (Fig. 1b, second trace) produces no hyperpolarizing response. The curare-induced depolarization persists even when $10 \mu \mathrm{M}$ curare is applied for up to $3 \mathrm{~min}$. These findings are all in agreement with the results of Ziskind and Dennis (1978) on freshly dissected embryonic muscle and demonstrate that cultured myotubes are a suitable preparation for studying the agonist action of curare.

Single-channel recordings, such as those shown in Figures 2 and 3 , were obtained at curare concentrations from 0.1 to $10 \mu \mathrm{M}$, with the membrane potential held at various levels over the range $-50 \mathrm{mV}$ to $-175 \mathrm{mV}$. Current records for cells treated for 1 to $3 \mathrm{hr}$ in $0.05 \mu \mathrm{M}$ $\alpha$-bungarotoxin, then exposed to $10 \mu \mathrm{M}$ curare, either contained no channel events at all or far too few for analysis. The fact that both curare-induced depolarization and curare-induced single-channel currents are
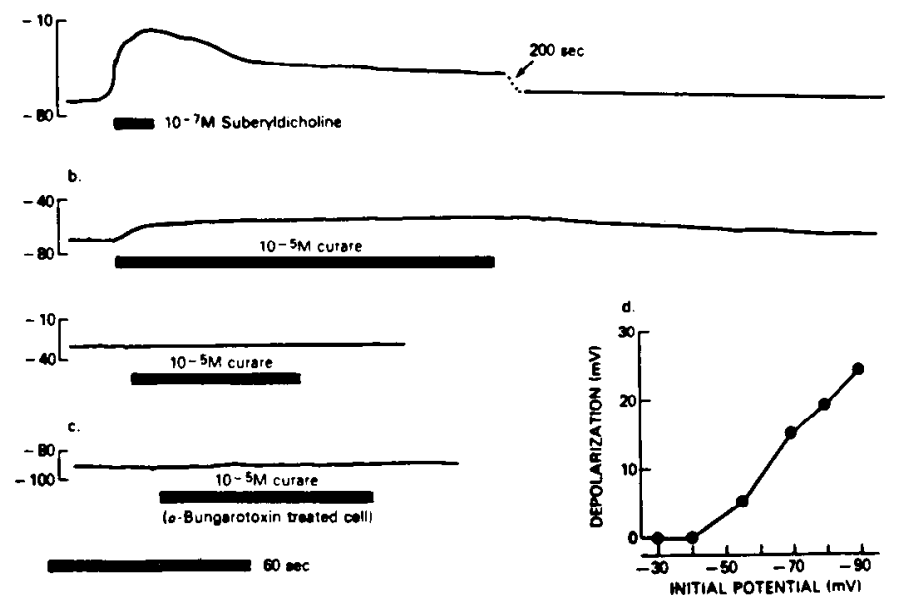

Figure 1. The depolarizing effect of curare on cultured embryonic rat muscle. For comparison, the effect of $0.1 \mu \mathrm{M}$ suberyldicholine is illustrated in $a$. The effect of $10 \mu \mathrm{M}(b)$ is much less pronounced, and when the cell is initially depolarized above $-50 \mathrm{mV}$, the drug shows no depolarizing action $(b$, lower trace). The voltage cutoff of the curare-induced response is demonstrated graphically in $d$. Cells preincubated with $\alpha$-bungarotoxin $(0.05 \mu \mathrm{M})$ for $1 \mathrm{hr}$ show no depolarizing response to curare (c).

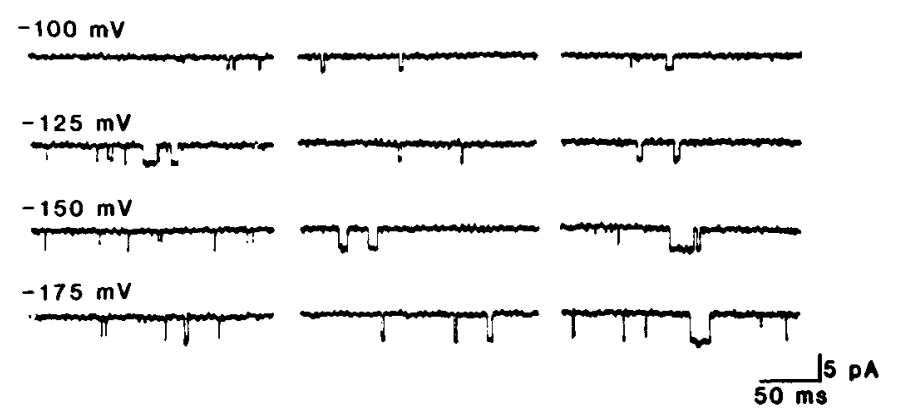

Figure 2. Sample of curare-induced channel activity recorded using $1 \mu \mathrm{M}$ curare. Data were recorded at a sampling rate of 1 point $/ 50 \mu \mathrm{sec}$. 

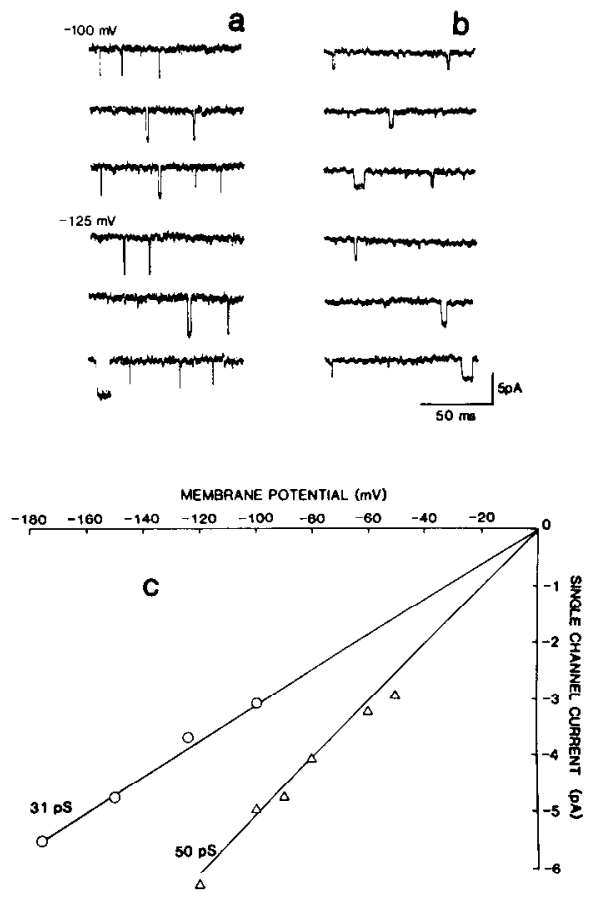

Figure 3. Single-channel activity from two separate patches of membrane showing the two conductance values observed. $a$, Fifty-pS channels; $b, 31$-pS channels; $c$, single-channel currentvoltage relations from the two membrane patches.

blocked by $\alpha$-bungarotoxin is good evidence that curare does indeed activate AChR channels in cultured embryonic muscle. No current jumps were observed in control experiments with saline-filled pipettes.

By probing the surface of the cell with the patch electrode, we compared the distribution of curare-activated channels with the distribution of cholinergic receptors determined from binding of fluorescent derivatives of $\alpha$-bungarotoxin (Sytkowski et al., 1973; Christian et al., 1980). The fluorescence probe studies show the AChRs of myotubes to be inhomogeneously distributed in the membrane, so that inhomogeneities in the intensity of curare-induced channel activity might be expected. When the patch electrode was probed over the cell surface, small areas were located in which noise, caused by the summation of single-channel currents from a large number of channels, was recorded instead of individual jumps. This suggests that curare activates channels in "hot spot" regions as well as in "background" regions of low channel density.

Figure $3, a$ and $b$, shows single-channel currents of two characteristic amplitudes obtained in cells from different cultures. Single-channel current-voltage relations are shown in Figure 3, demonstrating two distinct values of unit conductance, $31 \mathrm{pS}$ and $50 \mathrm{pS}$, measured for these two membrane patches. The two conductance values were generally measured in cells of different cultures. The earlier cultures studied had channels with $\sim 50 \mathrm{pS}$ conductance, whereas later cultures grown under nominally identical conditions produced exclusively $30 \mathrm{pS}$ channels (Table I). Our myotubes did not exhibit a mixture of the two types of channels in the presence of curare. However, we did observe the coexistence of both types of channels in patches treated with other agonists, as illustrated by the records of carbachol- and succinylcholine-induced currents in Figure 4. Over the period in which these curare measurements were being made, the cultures switched inexplicably at one point from producing exclusively the high-conductance channels to almost exclusively low-conductance channels. These changes did not correlate with any change in the culturing regimen. The 21 determinations summarized in Table I give a unit conductance of $30.4 \pm 3.5 \mathrm{pS}$. Typical of the earlier cultures was the value $47 \pm 6 \mathrm{pS}$ determined for four patches held at $-100 \mathrm{mV}$.

Cumulative histograms of channel open times are illustrated in Figure 5. For this example, as for all our data, the distribution is better fit by the sum of two exponentials than by a single exponential. When least squares fits were made for an exponential distribution to the histograms of jump durations, there was invariably a significant slow component. The data were then fit to a cumulative distribution function of the form

$$
N(t)=N_{f} \exp \left(-t / T_{f}\right)+N_{\mathrm{s}} \exp \left(-t / T_{\mathrm{s}}\right)
$$

Here, $N(t)$ denotes the number of events with duration greater than time, $t . T_{f}$ and $T_{s}$ are the mean durations for the fast and slow component, and $N_{f}$ and $N_{s}$ are the estimated number of each type of event. Since the quantities $N_{f}$ and $N_{s}$ are obtained by extrapolation to zero duration, the more significant quantity is their ratio, which gives the relative frequency of the two types of event. The cumulative distribution of Figure 5 allows direct estimate of $N_{s} / N_{f}$, the ratio of the two kinetic components.

In 21 experiments, the mean value of the fast time constant was $0.33 \pm 0.08 \mathrm{msec}$, and the mean value of the slow time constant was $1.84 \pm 0.43 \mathrm{msec}$. The ratio $N_{s} / N_{f}$ was variable from patch to patch with a mean of $0.30 \pm 0.17$. Thus, even ignoring the possibility of voltage dependence and curare concentration dependence of these time constants, they show coefficients of variation of only 0.24 (fast) and 0.23 (slow) evaluated for all the
CARBACHOL
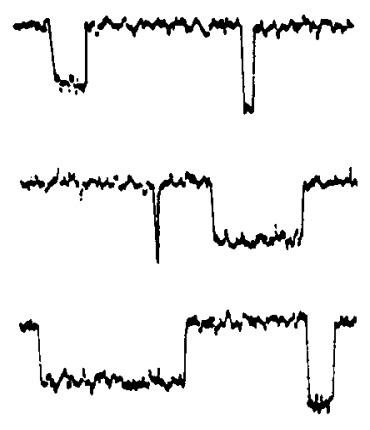

$-150 \mathrm{mV}$

\section{SUCCINYLCHOLINE}
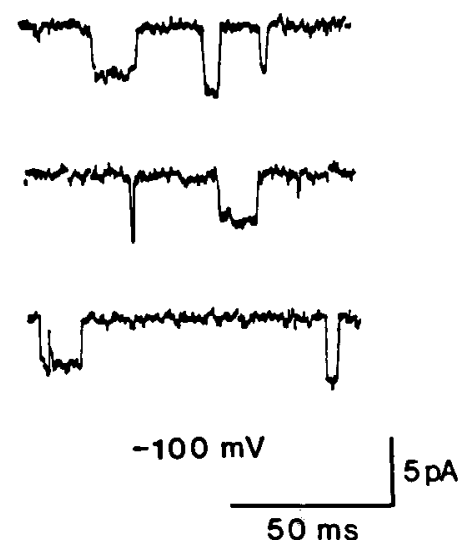

Figure 4. Coexistence of high- and low-conductance events in a single patch seen with the agonists carbamylcholine and succinylcholine. The coexistence of both conductance sizes was a relatively rare event which was observed with a number of agonists. 
TABLE I

Parameters determined from single-channel records

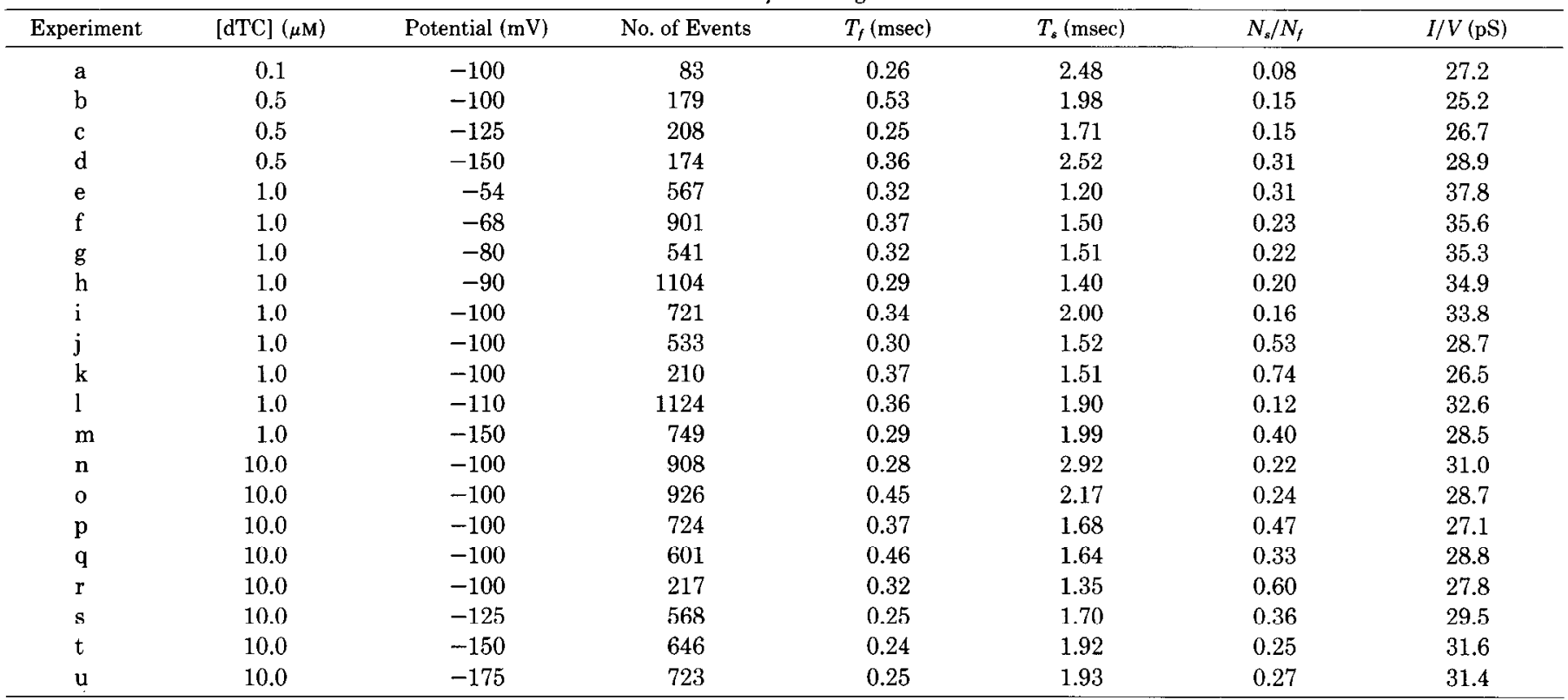

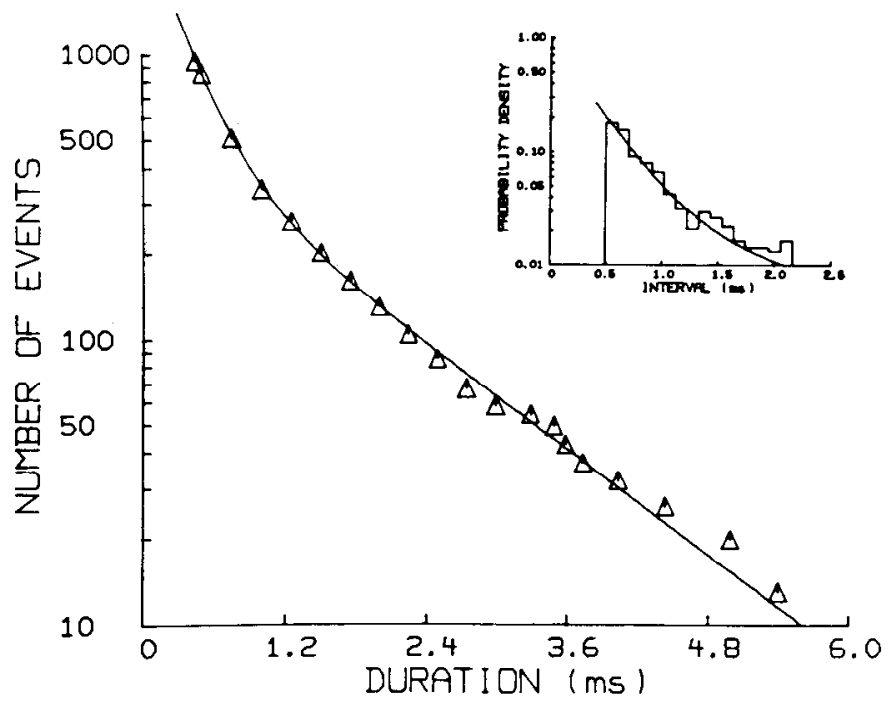

Figure 5. Cumulative histogram of channel open times for low-conductance channels from a membrane patch held at -90 $\mathrm{mV}$. The recording pipette contained $1 \mu \mathrm{M}$ curare. The ordinate shows the number of events with duration greater than or equal to the time $t$ plotted along the abcissa. The fitted line is an unweighted least squares fit to a distribution which is the sum of two exponentials. All 21 experiments were best fit to a twoexponential distribution, regardless of whether high- or lowconductance channels dominated. The inset to the figure shows a probability density histogram plotted for the same data. The ordinate gives the number of events per $0.1-\mathrm{msec}$ bin normalized by dividing by the total number of events. The record contained 1104 events and the parameters for best fit were: $T_{f}$ $=0.29 \mathrm{msec}, T_{s}=1.40 \mathrm{msec}, N_{s} / N_{f}=0.21$.

data. The ratio $N_{s} / N_{f}$ has a coefficient of variation of 0.57 , when no determinations are rejected. The data for all of the individual experiments are given in Table I. In seven earlier experiments with the high-conductance channels, we obtained $T_{f}=0.33 \pm 0.13 \mathrm{msec}, T_{s}=1.54$ $\pm 0.60 \mathrm{msec}$, and $N_{s} / N_{f}=0.23 \pm 0.07$.
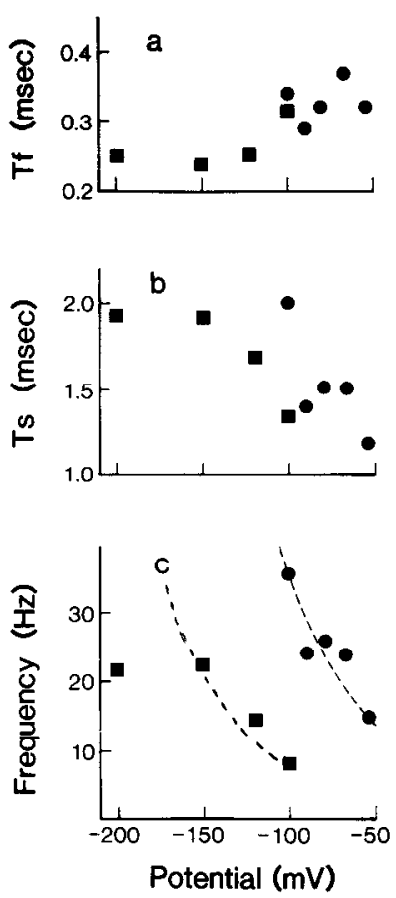

Figure 6. Fast open time (a), slow open time (b), and opening frequency $(c)$ as functions of membrane potential. Data were taken on two membrane patches $(\mathbf{0}, \mathbf{0})$ which could be held at the potentials indicated. Dashed curves were obtained by multiplying frequency at $-100 \mathrm{mV}$ by factor $\exp [(100-V) / 50]$. Circles correspond to the patch at $1 \mu \mathrm{M}$ curare, and squares correspond to the patch at $10 \mu \mathrm{M}$.

The macroscopic response, given in Figure 1d, shows that depolarization as a function of applied current does not occur beyond $-50 \mathrm{mV}$, in agreement with observations on intact embryonic muscle (Ziskind and Dennis, 1978). Since single-channel currents could be detected at $-50 \mathrm{mV}$, the most likely single-channel counterpart of the saturation is a voltage dependence of either the open- 
state lifetime or the opening frequency. To test which factor is most important, we must obtain current jump records for several potentials on a single patch. Figure 6 shows data from two patches which could be maintained at several different potentials. No significant potential dependence of the fast open time is discernible in Figure $6 a$, but the slow open time appears to increase with hyperpolarization. The main voltage dependence, however, is in the opening frequency, which is shown in Figure $6 c$ to decline by a factor of $e$-fold per $50-\mathrm{mV}$ depolarization (Fig. 6c, dashed curves). This voltage dependence is consistent with the macroscopic effect.

The fast time constant appears to be insensitive to curare concentration in the range of concentrations studied. The average value of $T_{f}$ was $0.33 \pm 0.03 \mathrm{msec}(9$ experiments) for $1 \mu \mathrm{M}$ curare and $0.33 \pm 0.09 \mathrm{msec}(8$ experiments) for $10 \mu \mathrm{M}$. The slow time constant, $T_{s}$, was $1.62 \pm 0.28 \mathrm{msec}$ (9 experiments) at $1 \mu \mathrm{M}$ and $1.91 \pm 0.47$ at $10 \mu \mathrm{M}$ (8 experiments).

Closed-time intervals for curare-induced channel activity have also been analyzed (Fig. $7 a$ ). In all cases, the interval histograms are well fit by a single exponential. As a check on this result, we also plotted the probability of a given number of jumps occurring in a fixed time interval, as shown in Figure $7 b$. The distributions fit reasonably well to a single-parameter Poisson distribution for the observed mean frequency. This is expected when the mean jump duration is much less than the
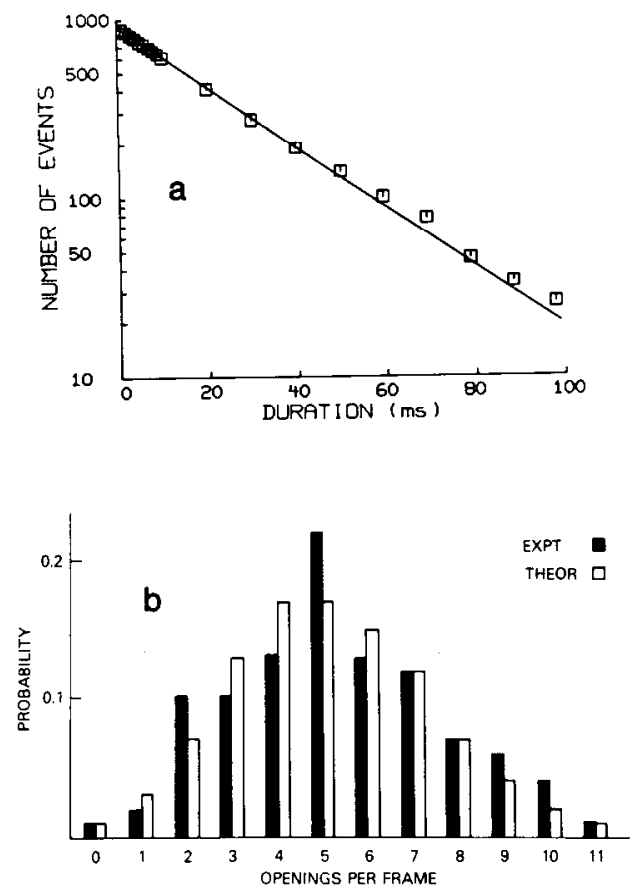

Figure 7. a, Distribution of intervals between jumps for a typical patch. The line shows best fit to an exponential distribution. No deviations from single-exponential distribution were evident in any of the experiments. Intervals were recorded with 1 msec resolution. $b$, Distribution of events recorded in randomly sampled 205-msec time segments. Theoretical probabilities are calculated from a Poisson distribution, with the observed mean frequency. The curare concentration was $1 \mu \mathrm{M}$. The patch was held at $-68 \mathrm{mV}$. The number of events was 902 , with a mean frequency of 5.27 events per frame $(25.7 / \mathrm{sec})$. mean interval between jumps and the number of fast channel reopenings is negligible.

\section{Discussion}

Our initial experiments demonstrated that cultured embryonic rat myotubes respond to curare in the same manner as excised embryonic muscle (Ziskind and Dennis, 1978). Curare depolarizes the muscle; the depolarization saturates at $-50 \mathrm{mV}$; curare-induced activation does not appear to desensitize. It is not surprising that the small depolarization produced by curare should have been overlooked during earlier studies, since cultured myotubes have resting potentials of about $-55 \mathrm{mV}$, very close to the cutoff.

From the single-channel data it is clear that curare has an agonist action on the AChR channel in embryonic muscle and that curare activation shares many features of activation by other cholinergic agonists (Lecar et al., 1982). The unit conductance is the same as for other agonists; two different conductance values $(30 \mathrm{pS}$ and 47 pS) are found; open-state lifetime distributions are fit by two exponentials. Trautmann (1982) has shown these two curare-induced conductance levels to coexist and has also observed a smaller 10-pS level. Such multiple conductance levels have been reported for cultured rat muscle with other agonists (Hamill and Sakmann, 1981) and also for Xenopus myocytes (Clark and Adams, 1982). In the latter case the proportion of the two conductance values was observed to vary from cell to cell.

Since curare channels have normal unit conductance, we must look to the channel activation kinetics for an explanation of the action of curare and other weak agonists. The two simplest kinetic schemes which have been proposed for the inability of partial agonists to yield full depolarization at receptor saturation are: (1) the channel has an intrinsically lower probability of being in the open state even at high agonist concentration because the rates of conformation change are limiting, or (2) the agonist acts at a separate site to block an activated channel. These two processes are not mutually exclusive, and recent evidence suggests that many agonists may block the channels they activate (Sine and Steinbach, 1983). One means of discriminating between these alternatives is to measure the agonist concentration dependence of the open time. Self-blocking may give rise to a decrease in open time with increasing agonist concentration, whereas the conformation rate explanation does not require any dependence of open time on agonist concentration. Trautmann (1982) showed, from single-exponential fits, that the open time (corresponding to our $T_{s}$ ) declined from $1.38 \pm 0.28 \mathrm{msec}$ at $10 \mu \mathrm{M}$ curare to 0.81 $\pm 0.29 \mathrm{msec}$ at $50 \mu \mathrm{M}$, suggesting that curare does indeed act as a channel blocker. From these measured values, we would expect the slow time constant to follow the relation

$$
T_{s}([\mathrm{dTC}])-(0.59+0.013[\mathrm{dTC}])^{-1}
$$

where [dTC] denotes curare concentration in micromolar concentration. Equation 2 predicts a value of $1.66 \mathrm{msec}$ at $1 \mu \mathrm{M}$ curare, which is in agreement with our measured value of $1.62 \pm 0.28 \mathrm{msec}$ taken from the nine measurements at that concentration in Table I. Unfortunately, 
the data at $10 \mu \mathrm{M}$ are too scattered to further test equation 2.

The dual action of curare as agonist and competitive antagonist on embryonic muscle at low concentrations is also consistent with an alternative explanation of partial agonist action whereby the efficacy of agonist action is determined by the rates of conformational transition between an activated closed state and the open state (Colquhoun, 1979). In all kinetic schemes having the sequence of binding reactions followed by a concentration-independent transition to an open state, the open probability for a fully liganded receptor depends only on the rates for the ultimate conformational transition. This limiting probability of being in an open state is given by $P_{o}=\beta /(\alpha+\beta)$, where $\beta$ and $\alpha$ are the rates for the opening and closing transitions. Thus, the quantity $P_{o}$ defines the limiting duty cycle for any agonist, with strong agonists having $P_{o}$ near one, and partial agonists having values near zero.

A model of this sort may also predict reopening or flickering when the channel opening rate is much greater than the agonist dissociation rate $\left(k_{d}\right)$. Flickering of the sort expected for large $\beta / k_{d}$ has been observed with other agonists (Nelson and Sachs, 1979; Sakmann et al., 1980; Colquhoun and Sakmann, 1981; Cull-Candy and Parker, 1982; Gration et al., 1982; Lecar et al., 1983) but was not in evidence in our curare records (Fig. 7). Curare's action may still be fit to such a scheme, however, provided that $\beta$ has a small value and $k_{d}$ a large value compared to the corresponding rates for stronger agonists.

Curare does indeed show a small value for the mean open time. For the two-exponential distribution of equation 1 , the mean open time is

$$
\bar{T}=\left(T_{f}+\left(N_{s} / N_{f}\right) T_{s}\right) /\left(1+\left(N_{s} / N_{f}\right)\right)
$$

For the averaged data of Table I, equation 3 gives $\bar{T}=$ 0.68 msec.

Trautmann (1982) observed a distinct kinetic pattern of transitions among the allowed conductance states, which would be related to a pattern of conductance change during a single drug occupancy. These transitions were not observed in our experiments, which were done at lower curare concentrations.

Curare is not peculiar in exhibiting double-exponential mean open-time distributions. We have tested several strong and weak agonists on different cultured muscle preparations and they all appear to show two-exponential open-time distributions (Jackson and Lecar, 1982; Jackson et al., 1982a, b; Lecar et al., 1982). The twoexponential open-time distribution implies the existence of two distinct open states. A recent analysis of correlation between the open times of successive openings of a channel suggests that only kinetic models in which the two open states are reached from separate precursor closed states will fit the data (Jackson et al., 1983). In one such model, the fast and slow components represent single- and double-liganded open states, so that the ratio $N_{s} / N_{f}$ would be expected to increase with agonist concentration. The data of Table I may show such a trend at low concentrations, but the measured ratios are too scattered to be conclusive.

Activation by curare may be a developmental peculi- arity of embryonic mammalian muscle, since curare (1 $\mathrm{mM}$ ) alters neither the membrane potential nor the conductance of embryonic avian muscle (Dryden and Thomson, 1980). Also, in a study of channel noise in embryonic amphibian muscle (Kullberg et al., 1981), curare, at a lower concentration, produced no effects other than antagonism of the $\mathrm{ACh}$ response. The effect is not confined to rat muscle, however, as single curare-activated channels have recently been observed in cultured human myotubes which, although derived from adult human biopsy material, share with embryonic muscle recent differentiation from a myoblast-like state (Jackson et al., 1982a).

It remains to be seen whether tissue culture conditions can be manipulated to make the AChRs of embryonic muscle inexcitable by curare. An understanding of the factors that make the weak agonist action of curare developmentally labile may help explain why some ligand-receptor interactions activate the channel and others do not.

\section{References}

Ascher, P., A. Marty, and T. O. Neild (1978) The mode of action of antagonists of the excitatory responses to acetylcholine in Aplysia neurones. J. Physiol. (Lond.) 278: 207235.

Christian, C. N., G. K. Bergey, M. P. Daniels and P. G. Nelson (1980) Cell interactions in nerve and muscle cell cultures. $J$. Exp. Biol. 89: 85-101.

Clark, R. B., and P. R. Adams (1982) ACh receptor populations in Xenopus myocyte membranes are non-homogeneous. Soc. Neurosci. Abstr. 7: 838.

Colquhoun, D. (1979) The link between drug binding and response: Theories and observations. In The Receptors: $A$ Comprehensive Treatise, pp. 93-142, Plenum Press, New York.

Colquhoun, D., and B. Sakmann (1981) Fluctuations in the microsecond time range of the current through single acetylcholine receptor ion channels. Nature (Lond.) 294: 464-466.

Cull-Candy, S. G., and I. Parker (1982) Rapid kinetics of single glutamate-receptor channels. Nature (Lond.) 295: 410-412.

Dryden, W. F., and C. M. Thomson (1980) Sodium conductance in developing muscle fibres. J. Physiol. (Lond.) 301: 75P$76 \mathrm{P}$.

Fambrough, D., and J. E. Rash (1971) Development of acetylcholine sensitivity during myogenesis. Dev. Biol. 26: 55-68.

Gration, K. A. F., J. J. Lambert, R. L. Ramsey, R. P. Rand, and P. N. R. Usherwood (1982) Closure of membrane channels gated by glutamate may be a two-step process. Nature (Lond.) 295: 599-601.

Hamill, O. P., and B. Sakmann (1981) Multiple conductance states of single acetylcholine receptor channels in embryonic muscle cells. Nature (Lond.) 294: 462-464.

Hamill, O. P., A. Marty, E. Neher, B. Sakmann, and F. J. Sigworth (1981) Improved patch-clamp techniques for highresolution current recording from cells and cell-free membrane patches. Pflugers Arch. 391: 85-100.

Horn, R., and J. Patlak (1980) Single channel currents from excised patches of muscle membrane. Proc. Natl. Acad. Sci. U. S. A. 77: 6930-6934.

Jackson, M. B., and H. Lecar (1982) Double-exponential chan nel current lifetime distributions in cultured nerve and muscle. Biophys. J. 37: 310a.

Jackson, M. B., H. Lecar, V. Askanas, and W. K. Engel (1982a) Single cholinergic receptor channel currents in cultured human muscle. J. Neurosci. 2: 1465-1473. 
Jackson, M. B., H. Lecar, D. A. Mathers, and J. L. Barker (1982b) Single channel currents activated by $\gamma$-aminobutyric acid, muscimol, and (-)-pentobarbital in cultured mouse spinal neurons. J. Neurosci. 2: 889-894.

Jackson, M. B., B. S. Wong, C. E. Morris, H. Lecar, and C. N. Christian (1983) Successive openings of the same acetylcholine-receptor channel are correlated in their open times. Biophys. J. 42: 109-114.

Kullberg, R. W., P. Brehm, and J. H. Steinbach (1981) Nonjunctional acetylcholine receptor channel open time decreases during development of Xenopus muscle. Nature (Lond.) 89: 411-413.

Lecar, H., C. Morris, and B. S. Wong (1982) Single channel recordings of weak cholinergic agonists. Biophys J. 37: 313a.

Lecar, H., C. Morris, and B. S. Wong (1983) Single-channel currents and the kinetics of agonist-induced gating. In Structure and Function in Excitable Cells, I. Tasaki, D. C. Chang, W. J. Adelman, and H. R. Leuchtag, eds., pp. 159-173, Plenum Publishing Corp., New York.

Morris, C. E., M. B. Jackson, H. Lecar, B. S. Wong, and C. N. Christian (1982) Activation of individual acetylcholine channels by curare in embryonic rat muscle. Biophys. J. 37: 19a.

Neher, E., B. Sakmann, and J. H. Steinbach (1978) The extracellular patch clamp: A method for resolving currents through individual open channels in biological membranes. Pflugers Arch. 375: 219-228.
Nelson, D., and F. Sachs (1979) Single ionic channels observed in tissue-cultured muscle. Nature (Lond.) 282: 861-863.

Nelson, P., C. Christian, and M. Nirenberg (1976) Synapse formation between clonal neuroblastoma $\times$ glioma hybrid cells and striated muscle cells. Proc. Natl. Acad. Sci. U. S. A. 73: $123-127$.

Sakmann, B., J. Patlak, and E. Neher (1980) Single acetylcholine-activated channels show burst-kinetics in presence of desensitizing concentrations of agonist. Nature (Lond.) 286: $71-73$.

Sigworth, F. J., and E. Neher (1980) Single $\mathrm{Na}^{+}$channel currents observed in cultured rat muscle cells. Nature (Lond.) 287: 447-449.

Sine, S. M., and J. H. Steinbach (1983) Agonists block current through acetylcholine receptor channels on $\mathrm{BC} 3 \mathrm{H} 1$ cells. Biophys. J. 41: 133a.

Sytkwoski, A. G., Z. Vogel, and M. W. Nirenberg (1973) Development of acetylcholine-receptor clusters in cultured muscle cells. Proc. Natl. Acad. Sci. U. S. A. 70: 270-274.

Trautmann, A. (1982) Curare can open and block ionic channels associated with cholinergic receptors. Nature (Lond.) 298: 272-275.

Ziskind L., and M. J. Dennis (1978) Depolarising effect of curare on embryonic rat muscles. Nature (Lond.) 276: 622623. 